\title{
O Papel da Visão na Aversão aos Espaços Abertos no Labirinto em Cruz Elevado
}

\author{
Silvio Morato ${ }^{1}$ \\ Universidade São Paulo - USP
}

O labirinto em cruz elevado é um dos modelos mais usados no estudo da ansiedade, medo e fármacos que alteram esses estados. Apesar da simplicidade aparente do modelo, diversos são os fatores que afetam o comportamento de ratos submetidos a esse modelo. Além disso, não se conhece exatamente quais os estímulos ambientais são os desencadeadores da aversão nesse modelo. O presente trabalho sugere que, em estudos onde os estímulos auditivos e olfativos são controlados, a aversão em ratos é desencadeada pela visão. A hipótese de trabalho é que os mecanismos mediadores da aversão (e estados emocionais concomitantes) são deflagrados pela entrada de luz e pela formação de imagens na retina dos animais. Para fundamentar essas hipóteses complementares, vários experimentos são analisados, cujos resultados favorecem uma, outra ou ambas as hipóteses. Finalmente, resultados obtidos com marcação da proteína c-Fos fornecem evidência neurofuncional que apóia as duas hipóteses sugeridas.

Descritores: Estados emocionais. Labirintos. Visão.

$\mathrm{O}$ labirinto em cruz elevado é um dos principais modelos usados no estudo da ansiedade. Surgiu dos experimentos com exploração e medo realizados no laboratório de Montgomery no século passado, nos anos 50, com um labirinto em Y elevado. Nesses trabalhos, observou-se uma menor utilização dos braços abertos em relação aos braços fechados e levantou a hipótese de que a estimulação provocada pela novidade (o ambiente novo) produzia reações de conflito entre medo e curiosidade, evidenciadas comportamentalmen-

1 Docente da Faculdade de Filosofia, Ciências e Letras de Ribeirão Preto - USP. Endereço eletrônico: smorato@ffclrp.usp.br 
te como tendências à esquiva e aproximação, respectivamente (Montgomery, 1955; Montgomery \& Monkman, 1955). Nesses estudos, o ambiente novo provocaria um aumento tanto do impulso para explorar como do medo, originando um conflito entre explorar e proteger-se.

O trabalho inicial com um labirinto em cruz elevado, parecido com o que existe hoje, foi desenvolvido por Handley e Mithani (1984), como um modelo para o estudo da ansiedade. Esse labirinto, após sofrer a modificação que lhe deu a forma existente hoje em dia, foi validado comportamental, fisiológica e farmacologicamente para ratos, por Pellow, Chopin, File e Briley (1985) e para camundongos, por Lister (1990). O método é considerado um instrumento útil e válido para medir ansiedade, investigando aspectos comportamentais, fisiológicos e farmacológicos (Anseloni \& Brandão, 1997; Cruz, Frei \& Graeff, 1994; Pellow et al., 1985; Rodgers \& Cole, 1994). O teste consiste em colocar o animal em um labirinto elevado do solo formado por dois braços fechados por paredes e dois abertos, analisando-se a frequiência de entradas e o tempo gasto em cada tipo de braço, e outros comportamentos como deslocamentos, levantar-se, esticar-se etc. $\mathrm{O}$ animal explora os dois tipos de braço mas entra mais e permanece mais tempo nos braços fechados. Considera-se a porcentagem da preferência (entradas e tempo gasto) pelos braços abertos e pelos fechados um índice fidedigno de ansiedade: quanto maiores os níveis de ansiedade, menor a porcentagem de entradas nos braços abertos e de tempo gasto nos mesmos (Handley \& Mithani, 1984; Pellow \& File, 1986).

Apesar da aparente simplicidade da situação de teste, muitos fatores influenciam a aversão aos braços abertos (para uma revisão, ver Hogg, 1996). Alguns deles são inerentes ao sujeito, como sexo (Imhof, Coelho, Schmitt, Morato, \& Carobrez, 1993; Johnston \& File, 1991), idade (Imhof et al., 1993) e estado nutricional (Almeida, Tonkins, \& Galler, 1996). Outros estão ligados ao procedimento experimental, como uma única ou múltiplas exposições ao labirinto (File, 1992; Griebel, Moreau, Jenck, Martin, \& Misslin, 1993; Treit, Menard, \& Royan, 1993) e a hora do dia em que o teste é feito (Gentsch, Lichtsteiner, Kraeuchi, \& Feer, 1982; Griebel et al., 1993). Além disso, manipulações experimentais também alteram o comportamento dos animais no teste do labirinto, tais como o tipo de transporte à sala de teste (Morato \& Brandão, 1996), o alojamento individual ou em grupo (Maisonnette, Morato, \& Brandão, 1993), e o tempo de permanência no biotério antes do teste (Morato \& Brandão, 1997). 
A causa da aversão aos braços abertos tem sido explicada por diferentes hipóteses. Inicialmente, propôs-se que essa aversão resultaria da esquiva natural que os roedores apresentam em relação à novidade (Montgomery, 1955). Posteriormente, sugeriu-se que a aversão pelos braços abertos resultaria do medo da altura (Pellow, 1986) e/ou dos espaços abertos (Barnett, 1975; Pellow et al., 1985). Treit e Fundytus (1989), no entanto, propuseram que a impossibilidade do animal realizar o comportamento de tigmotaxia — tendência de o animal permanecer com o corpo próximo a ou em contato com superfícies verticais - seria o estímulo aversivo associado aos braços abertos do labirinto. Grossen e Kelly (1972), justificam esse comportamento como uma estratégia evoluída para evitar predadores, sobretudo os predadores aéreos.

\section{A luz e o labirinto em cruz elevado}

Além dos fatores comentados acima outra característica da situação de teste também altera o comportamento exploratório no labirinto, a luminosidade da sala experimental. Já na década de 1980, Pellow et al. (1985) relataram que, quando são igualados os níveis de luminosidade nos dois tipos de braços, os animais não apresentam alterações significativas no número de entradas e tempo gasto nos braços abertos. Nessa mesma década, um experimento desenvolvido no nosso laboratório demonstrou que ratos testados no labirinto iluminado com luz vermelha (cor que os ratos não enxergam e equivale ao escuro) exibiram um aumento no número de entradas e tempo gasto nos braços abertos quando comparados com animais testados no labirinto iluminado (Morato \& Castrechini, 1989). Do mesmo modo, Griebel et al. (1993) encontraram que animais testados com iluminação reduziam significativamente a porcentagem de entradas e o tempo gasto nos braços abertos, assim como a atividade total. King e Jones (2001) relataram que níveis mais altos de luminosidade não alteraram o comportamento de ratos no campo aberto, na tábua de buracos (hole board) e no labirinto instável mas, quando o teste era realizado no escuro, observou-se um aumento na atividade locomotora (total de entradas nos braços aberto e fechado e na distancia total percorrida) e uma diminuição na esquiva dos braços abertos.

Nasello e colaboradores estudaram os efeitos da escuridão súbita sobre o comportamento exploratório no labirinto e demonstraram que os animais exi- 
biam um aumento na freqüência e porcentagem de entradas e tempo gasto nos braços abertos, assim como no total de entradas. Esse mesmo aumento na atividade locomotora foi observado quando se testavam os animais no campo aberto na ausência de luminosidade ou em situação de escuridão repentina (Nasello, Machado, Bastos, \& Felicio, 1998; Valle, 1970). No entanto, Becker e Grecksch (1996), utilizando três níveis de luminosidade na sala de teste do labirinto (30, 300 e 900 lux) e concluíram que o comportamento exploratório dos animais não se alterava em função dos níveis de luminosidade. Esses dados foram confirmado por um estudo paramétrico realizado em nosso laboratório no qual diferentes intensidades luminosas $(0,1,3,10,30,100$ e 300 lux $)$ foram investigadas em detalhe (Garcia, Cardenas, \& Morato, 2005). Nesse estudo demonstrou-se que o aumento da exploração dos braços abertos, só acontece no teste com níveis de iluminação 0 e 1 lux. A partir de 3 lux e até 300 lux essa exploração diminui, em comparação com 0 e 1 lux, mas não se modifica com os aumentos da luminosidade. Isso significa, que existe um ponto entre 1 e 3 lux no qual ocorre a diminuição da atividade exploratória. Além desse limiar, ressalte-se o fato de que esse fenômeno é do tipo tudo-ou-nada: alta exploração dos braços abertos sob 0 ou 1 lux e baixa (e semelhante) exploração de 3 a 300 lux.

Todos esses dados permitem perguntar por que a iluminação desencadeia nos animais os comportamentos de esquiva dos braços abertos, que claramente têm o efeito dos estímulos aversivos. No escuro os animais exploram igualmente os braços abertos e fechados. Em uma tentativa de descobrir se no escuro os animais empregavam outra modalidade sensorial, Cardenas, Lamprea e Morato (2001) cortaram bilateralmente as vibrissas em diferentes tamanhos a partir do folículo, interferindo com a tigmotaxia normal e testaram ratos no labirinto em cruz elevado sob condições de iluminação e escuro. Os ratos exploraram mais os braços abertos quando eram testados no escuro, em comparação com os testados no claro, mas mesmo sem as vibrissas, ou partes delas, exploraram o labirinto de modo semelhante aos ratos com vibrissas intactas tanto no claro quanto no escuro. Esses dados indicam que o sistema ligado às vibrissas não é a principal modalidade sensorial responsável pela exploração do labirinto em cruz elevado. E a questão permanece, será então a visão a modalidade sensorial à qual os ratos são sensíveis quando testados no labirinto? 


\section{A luz e a esquiva dos braços abertos}

Há um consenso na literatura de que os ratos são criaturas noturnas e plenamente adaptados a esse tipo de condição. Assim, apresentam olfato e audição bem desenvolvidos e visão pobre (Barnett, 1975). Uma hipótese que se pode levantar a esse respeito é que, por não enxergarem bem, os ratos, quando colocados nesses aparatos para teste, apresentariam medo e ansiedade que os fariam esquivar-se dos espaços abertos dos braços sem paredes. No entanto, Schiffman, Lore, Passafiume e Neeb (1970) sugeriram que, quando possível, os ratos utilizam a visão como principal sistema perceptivo para obter informações relevantes sobre o meio ambiente. Essa sugestão é compatível com os dados citados acima, obtidos com a exploração de ratos no escuro com diferentes aparatos de teste.

Essa sugestão foi também confirmada por outro trabalho realizado em nosso laboratório. Martinez, Cardenas, Lamprea e Morato (2002) investigaram o papel da presença de bordas transparentes circundando os braços abertos com diferentes alturas: 1, 5, 10, 20 e $40 \mathrm{~cm}$. Logo nos primeiros animais testados observou-se algo inesperado: os ratos evitaram os braços cercados pelo acrílico transparente de $40 \mathrm{~cm}$ de altura (a mesma altura das paredes de madeira dos braços fechados) da mesma forma que os ratos do grupo controle evitavam os braços abertos. É importante ressaltar que as paredes transparentes permitiam a tigmotaxia mas permitiam a visão desimpedida. Assim, dois outros grupos foram adicionadas ao estudo. Um deles foi testado com as paredes transparentes de $40 \mathrm{~cm}$ porém recobertas com papel branco translúcido. O outro foi testado nas mesmas condições, exceto que as paredes de acrílico transparentes foram recobertas por papel preto opaco. Nessas duas condições observou-se um aumento no comportamento exploratório nesses braços. Os ratos testados com as paredes transparentes recobertas pelo papel preto opaco exploraram esses braços igual à exploração que fizeram nos braços fechados por paredes de madeira; isto é, os quatro braços do labirinto foram explorados igualmente pelos ratos. Já os ratos testados com as paredes transparentes recobertas pelo papel branco translúcido exploraram esses braços em menor intensidade do que a exploração dos braços fechados pelas paredes de madeira, porém maior que a exploração dos braços abertos pelos ratos do grupo controle. Esse aumento na exploração dos braços cobertos com papel preto, 
em comparação com a parede transparente, levou os autores a proporem que o sistema visual seria um dos principais responsáveis na deflagração da aversão aos braços abertos.

Esses resultados permitiram ainda levantar duas hipóteses relacionadas. A primeira sugere que a mera entrada de luz horizontal (já que os raios verticais eram os mesmos para todos os grupos) na retina dos animais já é capaz de evocar aversão àqueles braços. Isso foi verificado no experimento descrito no parágrafo anterior, por aqueles ratos que, testados com a cobertura de papel branco translúcido, demonstraram exploração maior que o controle porém menor que os testados com papel preto opaco Como o papel branco translúcido permite a passagem de luz horizontal é provável que a mera entrada de luz na retina já seja capaz de deflagrar os mecanismos cerebrais que medeiam as respostas de esquiva. A segunda hipótese sugere que a formação de imagens na retina aumenta ainda mais a aversão deflagrada pela simples entrada de luz. Isso se baseia no fato de que os ratos evitaram entrar nos braços seja quando eram abertos seja quando eram circundados por paredes transparentes (o que permite tigmotaxia), que permitia que os animais enxergassem o exterior do labirinto; isto é, que se formassem imagens na retina. Essas duas últimas condições foram as que se mostraram mais aversivas, a julgar pela esquiva dos animais em entrar nesses tipos de braços.

Os testes das duas hipóteses levantadas no parágrafo anterior estão sendo feitos. Alguns resultados obtidos até então serão mostrados a seguir.

\section{A hipótese da entrada de luz na retina}

Parte da comprovação dessas duas hipóteses já existe na literatura, nos experimentos demonstrando que, na ausência de luz ratos entram mais no centro do campo aberto ou exploram igualmente os braços abertos e fechados em um labirinto em cruz elevado (Cardenas et al., 2001; Garcia et al., 2005; Griebel et al., 1993; King \& Jones, 2001; Morato \& Castrechini, 1989; Nasello et al., 1998; Valle, 1970). Isso mostra que, quando ratos são impedidos de enxergar (isto é, não há entrada de luz nem formação de imagens na retina) não demonstram medo e ansiedade. 
Claro

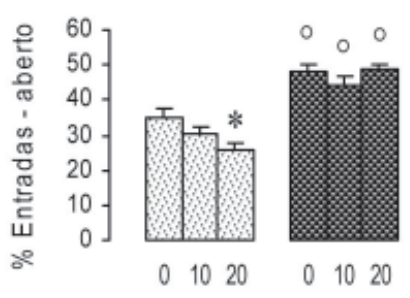

줐 Escuro

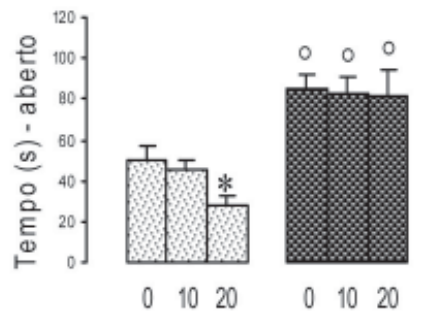

Pentilenotetrazol (mg/Kg)

Claro

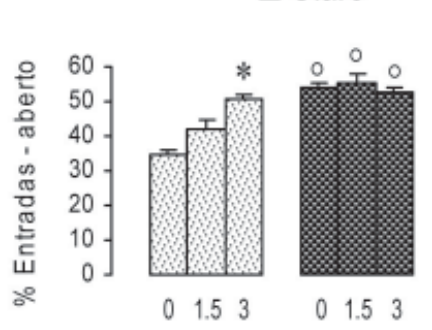

圆 Escuro

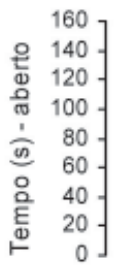

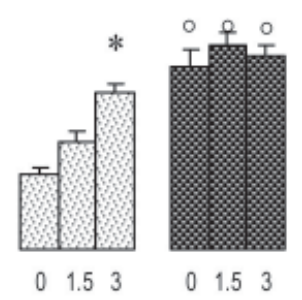

\section{Clordiazepóxido $(\mathrm{mg} / \mathrm{Kg})$}

Figura 1. Efeitos do pentilenotetrazol e do clordiazepóxido sobre a atividade exploratória de ratos testados no labirinto em cruz elevado no claro e no escuro. Barras representam as médias e os desvios são E. P. M. *, Diferente dos respectivos controles $(0 \mathrm{mg} / \mathrm{kg}){ }^{\circ}$, diferente do respectivo grupo testado no claro. (Anova seguida de Student-Newman-Keuls, $\mathrm{P}<0,05$ )

Um experimento realizado com drogas dá apoio a essa noção. Dois grupos de ratos foram submetidos ao labirinto em cruz elevado no claro (40 lux no centro do labirinto) ou no escuro. Metade dos animais foi distribuída em grupos que receberam diferentes doses de pentilenotetrazol $(0,10$ ou 20 $\mathrm{mg} / \mathrm{kg}$ ), uma droga que se liga ao sítio receptor da picrotoxina e inibe o funcionamento do receptor de GABA, causando aumento da ansiedade (Bell-Horner, Dibas, Huang, Drewe, \& Dillon, 2000; Huang et al., 2001; Jung, Lal, \& Gatch, 2002; Ramanjaneyulu \& Ticku, 1984). A outra metade foi distribuída em grupos que receberam diferentes doses de clordiazepóxido $(0,1,5$ ou 3,0 
$\mathrm{mg} / \mathrm{kg}$ ), droga de uso terapêutico que se liga ao sítio receptor da benzodiazepina e facilita a neurotransmissão de GABA, causando diminuição da ansiedade (Huang et al., 2001; Wong, Bottiglieri, \& Snead, 2003). A Figura 1 mostra que, como citado nos parágrafos anteriores, ratos testados no escuro não demonstraram ansiedade, explorando igualmente tanto os braços abertos quanto os fechados, ao contrário dos testados no claro, que evitaram mais os braços abertos. Como mostrado pela diminuição da exploração dos braços abertos, o pentilenotetrazol aumentou a ansiedade quando os ratos foram testados no claro, mas não quando testados no escuro. Na mesma direção, o clordiazepóxido diminuiu a ansiedade (isto é, aumentou a exploração dos braços abertos) apenas quando os ratos foram testados no claro mas não teve efeito quando foram testados no escuro. Esses efeitos comportamentais ligados à ansiedade foram específicos da diminuição da esquiva dos braços abertos e não ligados aos aspectos locomotores, uma vez que a exploração dos braços fechados foi a mesma, com ambas as drogas e com ambas as condições de iluminação. Esses dados também mostram que, no escuro, os mecanismos cerebrais res-

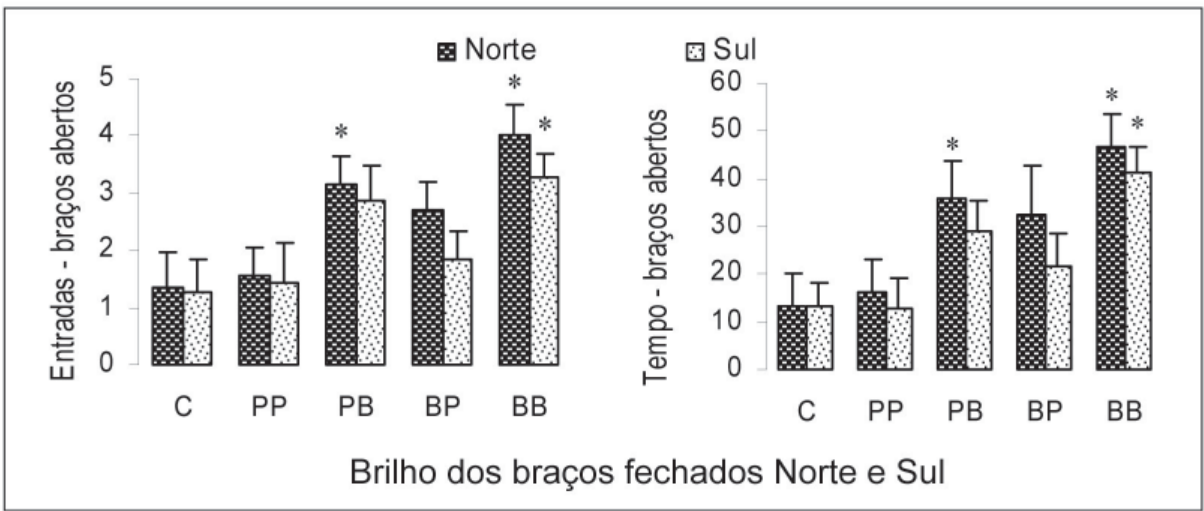

Figura 2. Efeito do brilho do forro das paredes fechadas sobre o comportamento exploratório de ratos nos braços abertos do labirinto em cruz elevado. Barras representam as médias e os desvios são E. P. M. C, Grupo controle; P, forro de cartolina opaca preta; B, forro de cartolina opaca branca. Norte e Sul designam cada um dos dois braços fechados *, diferente do respectivo grupo controle. (Anova seguida de Student-Newman-Keuls, $\mathrm{P}<0,05$ ) 
ponsáveis pela ansiedade não são deflagrados, já que o pentilenotetrazol, uma droga que notoriamente aumenta a freqüência e duração de comportamentos ligados à ansiedade e aversão, não foi capaz de produzir esses efeitos quando os animais estavam no escuro. Os dados ainda sugerem que drogas como essa não produzem ansiedade mas facilitam o funcionamento da circuitaria que o faz, que, no escuro, não entram em funcionamento.

Em um outro experimento, as paredes e o piso dos braços fechados foram forrados com cartolina opaca branca ou preta. (Os pisos receberam ainda uma cobertura de vidro não refletidor.) A Figura 2 mostra que, de um modo geral, quando as paredes dos braços fechados são forradas de cartolina branca (que reflete maior quantidade de luz que a preta), os ratos entram menos vezes e permanecem menos tempo nesses braços, aumentando, de modo compensatório, o número de entradas e o tempo gasto nos braços abertos. Sem entrar em outras discussões sobre a motivação dos animais para explorar os braços abertos, esses dados sugerem que a entrada de luz na retina (não a formação de imagens) aumentou a aversão dos braços fechados forrados de branco, quando comparados aos forrados de preto.

\section{A hipótese da formação de imagens na retina}

Em mais um experimento, um labirinto em cruz elevado teve seus braços abertos circundados por redomas de papelão (Figura 3). Quando os ratos saíam para um dos braços abertos, tinham a visão de uma redoma. O comportamento exploratório dos ratos com testados com essas redomas foi comparado ao de ratos testados no labirinto convencional, com os braços abertos não circundados por qualquer obstáculo. Havia três tipos de redoma com 1,20 m de altura: branca, preta e listrada (faixas verticais pretas e brancas de $15 \mathrm{~cm}$ de largura. Cada animal foi testado com apenas um tipo de redoma em uma única sessão. A Figura 4 mostra que a exploração dos braços abertos diminuiu quando esses eram circundados pela redoma listrada.

As características ópticas do olho de rato já foram bastante investigadas e alguns estudos (Artal, Tejada, Tedó, \& Green, 1997; Block, 1968) mostram que o rato é hipermétrope, como aliás também outros mamíferos de mesmo porte e hábitos noturnos. Essa característica prejudicaria a visão 


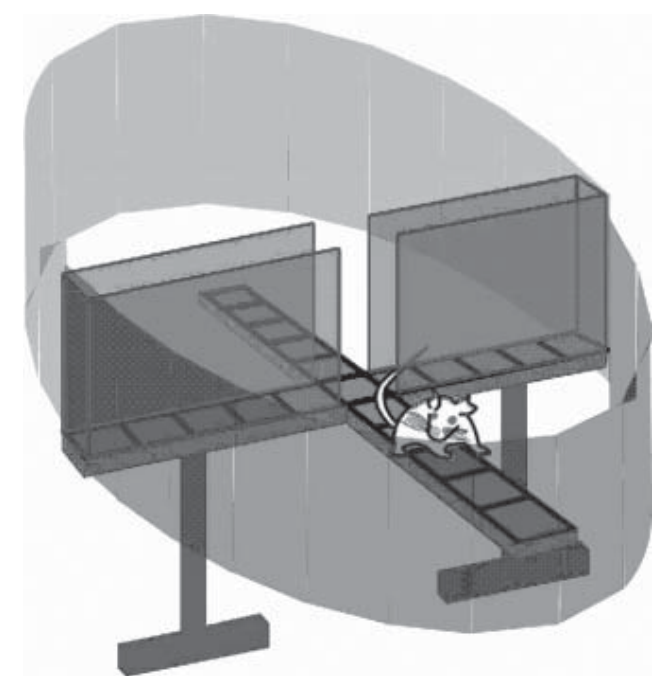

Figura 3. Esquema do labirinto em cruz elevado mostrando o uso das redomas.
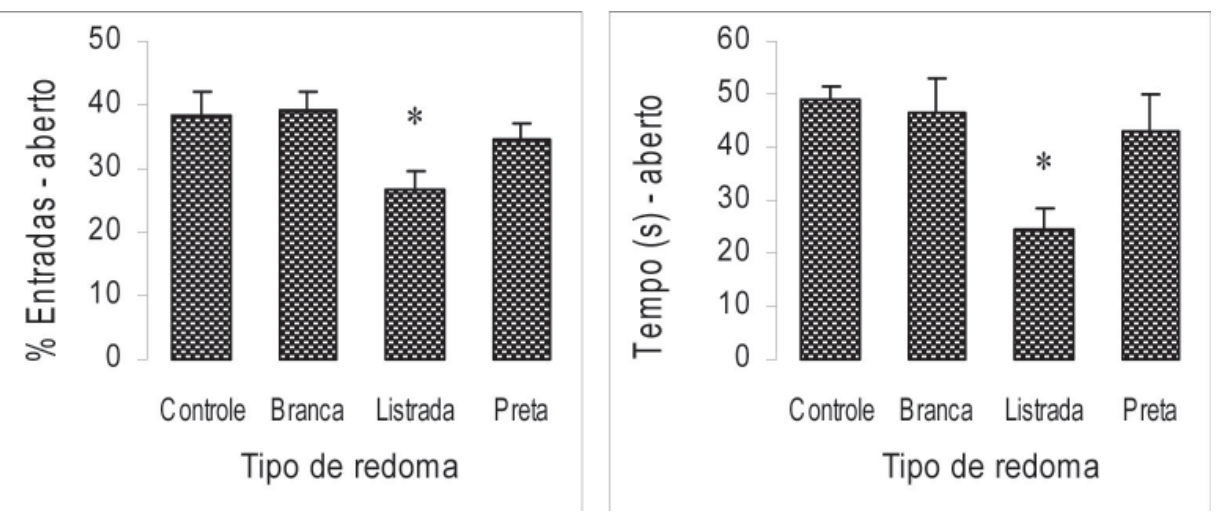

Figura 4. Efeito dos padrões das redomas circundando os braços abertos do labirinto em cruz elevado sobre a exploração dos mesmos por ratos. Barras representam as médias e os desvios são E. P. M. *, diferente do respectivo grupo controle. (Anova seguida de Student-Newman-Keuls, $\mathrm{P}<0,05$ ) 
a distâncias curtas. A acuidade visual, outra variável de interesse quanto às características ópticas do olho do rato, pode ser definida como o menor ângulo visual que permite que alguma propriedade da estimulação seja discriminada. Uma medida freqüentemente empregada para averiguar a acuidade é a função de sensibilidade ao contraste, que relaciona a intensidade do contraste com frequiência espacial de um estímulo na resposta de neurônios individuais. Por isso foram usadas listras pretas e brancas no campo visual visto dos braços abertos do labirinto. Assim, as redomas listradas, com contrastes que estimulavam a retina dos ratos, foram as que desencadearam maior aversão aos braços abertos. Portanto, a segunda hipótese parece ser fortalecida por esses resultados.

\section{Evidência neurofuncional}

Finalmente, foi realizado um estudo comparando alterações funcionais no cérebro dos ratos usando marcação da proteína $c$-Fos. No final da década de oitenta, a descoberta de que ao serem estimulados, os neurônios expressam transitoriamente o proto-oncogene $c$-fos (Sagar, Sharp, \& Curran, 1988) acrescentou uma nova dimensão ao conceito de anatomia funcional, permitindo determinar com grande precisão quais áreas cerebrais estavam mais ativas em um dado momento. Os dados da Figura 5 são parte de um conjunto mais amplo de resultados e são mostrados a título de exemplo de como a entrada de luz ou a formação de imagens na retina dos ratos podem alterar diferencialmente o funcionamento de diferentes áreas do cérebro. As áreas aqui mostradas relacionam-se de alguma forma com a mediação de comportamentos frente a situações aversivas, potencialmente desencadeadoras de medo e ansiedade. Do ponto de vista comportamental, os ratos testados no claro evitaram explorar os braços abertos enquanto os testados no escuro exploraram igualmente os braços fechados e abertos do labirinto; os ratos do grupo controle apenas permaneceram no biotério em suas gaiolas-viveiro. Portanto, quaisquer diferenças com esses animais poderiam ser atribuídas ao tipo de teste empregado, no presente caso, labirinto no claro ou labirinto no escuro. 


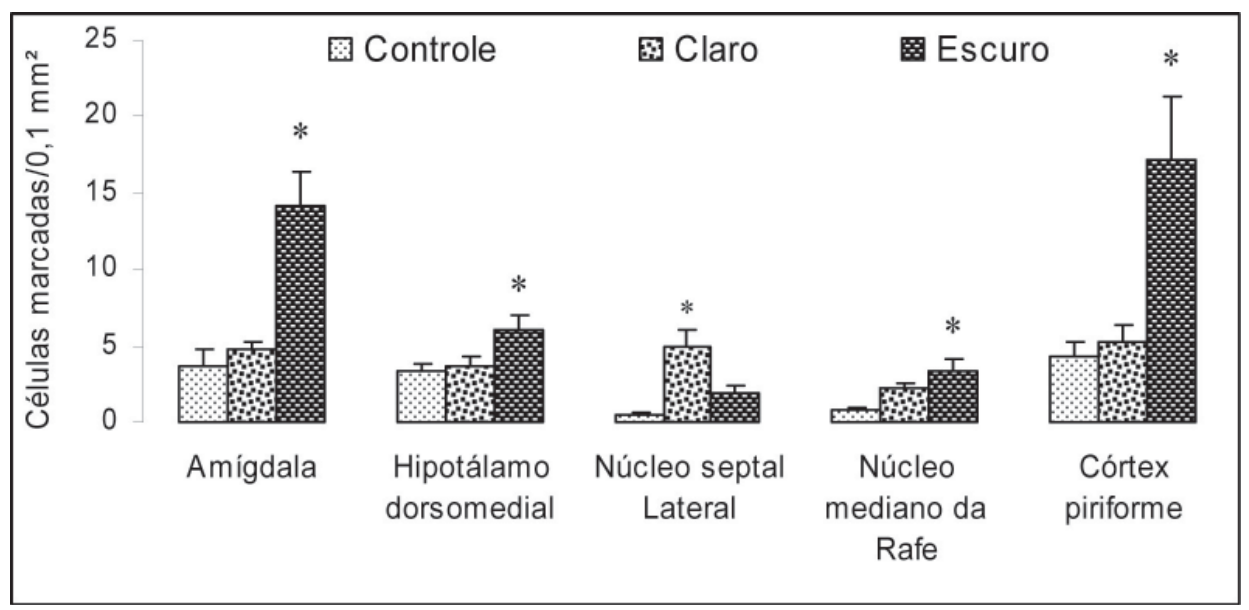

Figura 5. Número de células marcadas por $0,1 \mathrm{~mm}^{2}$ em áreas do cérebro de ratos testados no labirinto em cruz elevado no claro e no escuro. Barras representam as médias e os desvios são E. P. M. Os controles foram ratos que permaneceram todo o tempo no biotério. *, diferente do respectivo controle. (Anova seguida de Student-Newman-Keuls, $\mathrm{P}<0,05$ )

\section{Conclusão}

Dessa forma, há um corpo de evidência sugerindo que uma modalidade sensorial importante na deflagração da aversão (e dos comportamentos associados à esquiva e fuga dessas situações) é a visão. Essa conclusão vai na contramão da literatura, que de modo geral considera os ratos animais de hábitos noturno e cujo mundo sensorial seria basicamente olfativo e auditivo. A evidência apresentada obviamente não nega a importância dessas modalidades sensoriais. Apenas acrescenta que os ratos também empregam a visão para detectar situações que exigem reações adequadas a perigos potenciais. Os experimentos citados aqui foram realizados em locais onde os estímulos olfativos e auditivos foram controlados (ou pelos menos assim se tentou) para se manterem sempre nos mesmos níveis, afetando o comportamento dos ratos o mínimo possível.

Morato, S. (2006). The role of vision in the aversion to the open spaces in the elevated plus-maze. Psicologia USP, 17(4), 159-174. 


\begin{abstract}
The elevated plus-maze is one of the most used models to study anxiety, fear and drugs that alter these states. In spite of the apparent simplicity of the model there are several factors that affect the behavior of rats submitted to this test. Besides, the actual environmental stimuli triggering aversion in this model are not known. The present work suggests that, in studies where auditory and olfactory stimuli are controlled, aversion in rats is triggered by vision. The hypothesis advanced is that the mechanisms mediating aversion (and the concomitant emotional states) are triggered by light entering the rats' retina and by images forming in it. In order to fundament these two complementary hypotheses, several experiments are analyzed, the results of which favor one, other or both hypotheses. Finally, results obtained with protein c-Fos staining supply neurofunctional evidence that supports both suggested hypotheses.
\end{abstract}

Index terms: Emotional states. Mazes. Vision.

Morato, S. (2006). Le rôle de la vision dans la aversion a les espaces ouverts d'un labyrinthe en croix élevé. Psicologia USP, 17(4), 159-174.

Résumé: Le labyrinthe en croix élevé est un des plus employés modèles pour l'étude d' anxiété, peur et des drogues que modifient ces états émotionnelles. Malgré sa simplicité apparente, il y a plusieurs de facteurs affectant le comportement des rats soumis a ce modèle. D'autre part, on ne connais pas exactement quelles sont les stimulations environnementales déclenchant l'aversion dans ce modèle. Le présent travail suggère que, dans les études où les stimulations auditifs et olfactifs sont contrôlés, l'aversion chez les rats est déclenché par la vision. L' hypothèse de travail est que les mécanismes médiateurs de la aversion (et des états émotionnelles concomitants) sont déclenchés par l'entrée de la lumière et par la formation d'images chez la rétine de ces animaux. Pour légitimer ces hypothèses complémentaires, plusieurs expériences sont analysés, dont les résultats privilégient un et l'autre hypothèse. Finalement, résultats obtenues avec la marquage de la protéine $c$-Fos portent évidence neurofonctionnelle soutient les deux hypothèses suggérés.

Mots-clés: États émotionnelles. Labyrinthes. Vision. 


\section{Referências}

Almeida, S. S., Tonkins, J., \& Galler, J. R. (1996). Prenatal protein malnutrition affects exploratory behavior of female rats in the elevated plus-maze test. Physiology and Behavior, 60, 675-680.

Anseloni, V. Z., \& Brandão, M. L. (1997). Ethopharmacological analysis of behavior of rats using variations of the elevated plus-maze. Behavioural Pharmacology, 8, 533-540.

Artal, P., Tejada, P. H. de, Tedó, C. M., \& Green, D. G. (1998). Retinal image quality in the rodent eye. Visual Neuroscience, 15, 597-605.

Barnett, S. A. (1975). The rat: A study in behavior. Chicago: University of Chicago Press.

Becker, A., \& Grecksch, G. (1996). Illumination has no effect on rats' behavior in the elevated plus-maze. Physiology and Behavior, 59, 175-177.

Bell-Horner, C. L., Dibas, M., Huang, R. Q., Drewe, J. A., \& Dillon, G. H. (2000). Influence of subunit configuration on the interaction of picrotoxin-site ligands with recombinant GABA(A) receptors. Molecular Brain Research, 76(1), 47-55.

Block, M. T. (1969). A note on the refraction and image formation in the rat's eye. Vision Research, 9, 705-711.

Cardenas, F., Lamprea, M. R., \& Morato, S. (2001). Vibrissal sense is not the main sensory modality in the rat exploratory behavior in the elevated plus-maze. Behavioural Brain Research, 122, 169-174.

Cruz, A. P. M., Frei, F., \& Graeff, F. G. (1994). Ethopharmacological analysis of rat behavior on the elevated plus-maze. Pharmacology Biochemistry and Behavior, 49,171-176.

File, S. E. (1992). Behavioural detection of anxiolytic action. In J. M. Elliott, D. J. Heal \& C. A. Marsden (Orgs.), Experimental approaches to anxiety and depression (pp. 25-44). New York: John Wiley \& Sons.

Garcia A. M. B., Cardenas F. P., \& Morato S. (2005). Effect of different illumination levels on rat behavior in the elevated plus-maze. Physiology and Behavior, 85, 265-270.

Gentsch, C., Lichtsteiner, M., Kraeuchi, K., \& Feer, H. (1982). Different reaction patterns in individually and socially reared rats during exposures to novel environments. Behavioural Brain Research, 4, 45-54.

Griebel, G., Moreau, J-L., Jenck, F., Martin, J. R., \& Misslin, R. (1993). Some critical determinants of the behaviour of rats in the elevated plus-maze. Behavioural Processes, 29, 37-48.

Grossen, N. E., \& Kelly, M. J. (1972). Species-specific behavior and acquisition of avoidance behavior in rats. Journal of Comparative and Physiological Psychology, 81, 307-310. 
Handley, S. L., \& Mithani, S. (1984). Effects of alpha-adrenoceptor agonists and antagonists in a maze-exploration model of 'fear'- motivated behaviour. Naunyn-Schmiedeberg's Archives of Pharmacology, 327, 1-5.

Hogg, S. (1996). A review of the validity and variability of the elevated plus-maze as an animal model of anxiety. Pharmacology Biochemistry and Behavior, 54, 21-30.

Huang, R., Bell-Horner, C. L., Dibas, M. I., Covey, D. F., Drewe, J. A., \& Dillon, G. H. (2001). Pentylenetetrazole-induced inhibition of Recombinant-g-Aminobutyric Acid Type A (GABAa) Receptors: Mechanism and site de action. Journal of Pharmacology and Experimental Therapeutics, 298, 986-994.

Imhof, J. T., Coelho, Z. M. I., Schmitt, M. L., Morato, G. S., \& Carobrez, A. P. (1993). Influence of gender and age on performance of rats in the elevated plus-maze apparatus. Behavioral Brain Research, 56, 177-180.

Johnston, A. L., \& File, S. E. (1991). Sex differences in animal tests of anxiety. Physiology and Behavior, 49, 245-250.

Jung, M. E., Lal, H., \& Gatch, M. B. (2002). The discriminative stimulus effects of pentylenetetrazol as a model of anxiety: Recent developments. Neuroscience and Biobehavioral Reviews, 26, 429-439.

King, S. M., \& Jones, N. (2001). Influence of circadian phase and test illumination on preclinical models of anxiety. Physiology and Behavior 72, 99-106.

Lister, R. G (1990). Ethological-based animal models of anxiety disorders. Pharmacological Therapy, 46, 321-340.

Maisonnette, S., Morato, S., \& Brandão, M. L. (1993). Role of resocialization and of 5HT1A receptor activation on the anxiogenic effects induced by isolation in the elevated plus-maze test. Physiology and Behavior, 54, 753-758

Martinez, J. C., Cardenas, F., Lamprea, M., \& Morato, S. (2002). The role of vision and proprioception in the aversion of rats to the open arms of an elevated plus maze. Behavioral Processes, 60,15-26.

Montgomery, K. C. (1955). The relation between fear induced by novel stimulation and exploratory behavior. Journal of Comparative Physiology and Psychology, 48, 254-260.

Montgomery, K. C., \& Monkman, J., A. (1955). The relation between fear and exploratory behavior. Journal of Comparative and Physiological Psychology, 48, 132-136.

Morato, S., \& Brandão, M. L. (1996). Transporting rats to the test situation on a cart can modify rat exploratory behavior in the elevated plus-maze. Psychobiology, 24, 247-252.

Morato, S., \& Brandão, M. L. (1997). Paradoxical increase of exploratory behavior in the elevated plus-maze by rats exposed a two kinds of aversive stimuli. Brazilian Journal of Medical and Biological Research, 30, 1113-1120. 
Morato, S., \& Castrechini, P. (1989). Effects of floor and environmental illumination on exploratory activity in the elevated plus-maze. Brazilian Journal of Medical and Biological Research, 22, 707-710.

Nasello, A. G., Machado, C., Bastos, J. F., \& Felicio L. F. (1998). Sudden darkness induces a high activity-low anxiety state in male and female rats. Physiology and Behavior, 63, 451-454.

Pellow, S. (1986). Anxiolytic and anxiogenic drug effects in a novel test of anxiety: A exploratory model of anxiety in rodents valid? Methods and Findings in Experimental Clinical Pharmacology, 8, 557-565.

Pellow, S., \& File, S. E. (1986). Anxiolytic and anxiogenic drug effects on exploratory activity in elevated plus-maze: A novel test of anxiety in the rat. Pharmacology, Biochemistry and Behavior, 24, 525-529.

Pellow, S., Chopin, P., File, S. E., \& Briley, M. (1985). Validation of open-closed arm entries in an elevated plus-maze as a measure of anxiety in the rat. Journal of Neuroscience Methods, 14, 149-167.

Ramanjaneyulu, R., \& Ticku, M. K. (1984). Interactions of pentamethylenetetrazole and tetrazole analogues with the picrotoxinin site of the benzodiazepine-GABA receptorionophore complex. European Journal of Pharmacology, 98, 337-345.

Rodgers, R. J., \& Cole, J. C.(1994). The elevated plus-maze: Pharmacology, methodology and ethology. In S. J. Cooper \& C. A. Hendrie (Orgs.), Ethology and psychopharmacology (pp. 9-43). New York: John Wiley and Sons.

Sagar, S. M., Sharp, F. R., \& Curran, T. (1988). Expression of Fos protein in brain: Metabolic mapping at the cellular level. Science, 240, 1328-1331.

Schiffman, H. R., Lore, R., Passafiume, J., \& Neeb, R. (1970). Role of vibrissae for depth perception in the rat (Rattus novergicus). Animal Behavior, 18, 290-292.

Treit, D., \& Fundytus, M. (1989). Thigmotaxis as a test for anxiolytic activity in rats. Pharmacology, Biochemistry and Behavior, 31, 959-962.

Treit, D., Menard, J., \& Royan, C. (1993). Anxiogenic stimuli in the elevated plus-maze. Pharmacology Biochemistry and Behavior, 44, 463-469.

Valle, F. P. (1970). Effects of strain, sex, and illumination on open-field behavior of rats. American Journal of Psychology, 83, 103-111.

Wong, C. G. T., Bottiglieri, T., \& Snead. O. C. (2003). GABA, g-hydroxybutyric acid, and neurological disease. Annals of Neurology, 54, (Suppl. 6), S3-S12.

Recebido em: 17/11/2006

Aceito em: 27/11/2006 